\title{
Hydrogen Peroxide Production in Chronic
}

\section{Granulomatous Disease}

\author{
A CYTOCHEMICAL STUDY OF REDUCED PYRIDINE \\ NUCLEOTIDE OXIDASES
}

\author{
Richard T. Briggs, Manfred L. Karnovsky, and Morris J. Karnovsky \\ From the Departments of Pathology and Biological Chemistry, Harvard Medical School, \\ Boston, Massachusetts 02115
}

A B S TRACT The ability of polymorphonuclear leukocytes (PMN) to produce $\mathrm{H}_{2} \mathrm{O}_{2}$ in response to phagocytic stimulation was examined cytochemically using leukocytes from normal individuals and patients with chronic granulomatous disease (CGD). Normal PMN oxidized diaminobenzidine within the phagocytic vacuole by a reaction dependent upon endogenous $\mathrm{H}_{2} \mathrm{O}_{2}$ and myeloperoxidase. CGD PMN failed to oxidize diaminobenzidine, which is consistent with the biochemical data showing a lack of $\mathrm{H}_{2} \mathrm{O}_{2}$-generating capacity. A plasma membrane enzyme (oxidase) activated by phagocytosis is capable of $\mathrm{H}_{2} \mathrm{O}_{2}$ production in PMN. The localization of this oxidase activity was explored in CGD PMN using a cytochemical technique specific for $\mathrm{H}_{2} \mathrm{O}_{2}$. The enzyme activity is stimulated by exogenous NADH, but not NADPH. Reaction product formation, indicative of activity of the oxidase, is dependent upon precipitation of cerium ions by the enzymatically generated $\mathrm{H}_{2} \mathrm{O}_{2}$. The advantage of this approach is that enzyme activity of individual cells can be assessed, allowing determination of numbers of reactive cells in the population and their relative degrees of reactivity. NADH oxidase was found to be active both on the plasma membrane and within the phagocytic vacuoles of control PMN, whereas those cells from three CGD patients showed greatly reduced activity in both these sites. Assessment of the reactivity of individual cells showed the number of cells with oxidase activity in CGD to be significantly reduced when compared to control values. Additionally, of those cells that do react, a higher percentage of them are only weakly reactive. Omission of NADH from

Received for publication 17 November 1976 and in revised form 21 February 1977. the incubation medium reduced the percentage of control cells showing enzyme activity but had no effect on CGD PMN, implying that the enzyme is not saturated with substrate in control cells, but in CGD the diminished enzyme is fully saturated. The defect may lie in the fact that in CGD patients there are fewer cells capable of peroxide generation, and a majority of these reactive cells produce only reduced amounts of this bactericidal agent.

\section{INTRODUCTION}

Phagocytosis by normal human polymorphonuclear leukocytes $(\mathrm{PMN})^{1}$ is accompanied by an increase in aerobic metabolism. This respiratory burst includes a cyanide-insensitive increase in oxygen consumption (1), an increase in both superoxide $(2,3)$ and hydrogen peroxide $(4,5)$ production, and stimulation of the hexose monophosphate shunt (6). It is generally agreed that a reduced pyridine nucleotide oxidase underlies this augmented respiratory activity, but whether NADPH oxidase or NADH oxidase is the primary enzyme remains unclear. The roles of both enzymes in the oxidative metabolism of the intact PMN require clarification. Oxidation of NADH is capable of generating $\mathrm{H}_{2} \mathrm{O}_{2}$, a reaction product which is found both extracellularly and intracellularly $(5,7)$. The presence of $\mathrm{H}_{2} \mathrm{O}_{2}$ within the phagocytic vacuole, where it presumably is involved in the bactericidal activity of the PMN (8), has been suggested by many workers (9-11) and has been demonstrated cytochemically (12). An oxidase activity that utilizes NADH but not

\footnotetext{
${ }^{1}$ Abbreviations used in this paper: CGD, chronic granulomatous disease; DAB, 3,3'-diaminobenzidine; Hanks' BSS, Hanks' balanced salt solution; $\mathrm{O}_{2}^{-}$, superoxide; $\mathrm{PMN}$, polymorphonuclear leukocyte; PS, polystyrene.
} 
$\mathrm{NADPH}^{2}$ was originally found in the soluble portion of the cell (13-15); such an activity has also been found associated with the plasma membrane (16-18). As a plasma membrane enzyme, the $\mathrm{NADH}$ oxidase is internalized during phagocytosis and retains its peroxide-generating activity within the phagocytic vacuole (17). NADPH-oxidizing activity has been associated biochemically with the particulate fraction of PMN $(19,20) . \mathrm{Mn}^{++}$was originally found to be necessary for optimal manifestation of this activity, but later work has shown that its action is artifactual $(21,22)$. Even in the absence of this metal, the action of this particulate fraction towards NADPH is considered by some workers to be an important mechanism in the function of the cell (e.g., 23, 24).

In chronic granulomatous disease (CGD), there is no respiratory burst accompanying particle uptake (25, 26). Hexose monophosphate shunt activity is not stimulated, and $\mathrm{H}_{2} \mathrm{O}_{2}(25,27)$ and superoxide $\left(\mathrm{O}_{2}^{-}\right)(28,29)$ production are not increased after phagocytic stimulation. This results in impaired killing of certain microorganisms. The exact nature of the defect remains unclear. Morphologically, the resting cells appear normal, and comparative studies of the morphology and rates of degranulation of phagocytizing normal and CGD PMN show only minor differences $(30,31)$. It is generally agreed that the major lesion involves the oxidase responsible for the respiratory burst. NADPH oxidase activity from granules of CGD patients has been shown to be reduced to about $8 \%$ of normal (32) or less (23). Abnormally low levels of NADH oxidase have been reported as well $(15,16,33)$. Evidence refuting these observations has also been adduced (25), resulting in as yet unreconciled discrepancies. The exact level of the defect, that is whether it is a reduced amount of enzyme, failure of enzyme activation, decreased availability of substrate, or some other misfunction, is unclear. Stimulation of the hexose monophosphate shunt (34) and improved bactericidal activity (35) in leukocytes from CGD patients have been accomplished by insertion of an $\mathrm{H}_{2} \mathrm{O}_{2}$-generating system into the cells.

Since one property of CGD granulocytes is an impaired peroxide production, it was thought that closer examination of the sites of an NADH-stimulated, $\mathrm{H}_{2} \mathrm{O}_{2}$-generating oxidase by a recently developed cytochemical technique (17) might provide further information regarding this abnormality. To detect possible differences in NADH oxidase distribution and activity between normal and CGD PMN, the cytochemical approach seemed ideal. Since the activity

2 The terms "NADH oxidase" or "NADPH oxidase" will be used, meaning, simply, enzymatic activities with demonstrated preference for one or the other substrate under the conditions employed by various laboratories. of individual cells is assessed, heterogeneity within the population, with regard to NADH oxidase activity, could also be quantitated. Two different approaches were used. Initially, the diaminobenzidine (DAB) technique (12) was used to determine the presence or absence of $\mathrm{H}_{2} \mathrm{O}_{2}$ in the phagocytic vacuole of CGD PMN. This test, dependent on the oxidation of DAB by endogenous $\mathrm{H}_{2} \mathrm{O}_{2}$ and myeloperoxidase, showed reduced amounts of peroxide in CGD phagocytic vacuoles. The sites of synthesis of $\mathrm{H}_{2} \mathrm{O}_{2}$ by $\mathrm{NADH}$ oxidase were then examined by the cerium technique in which enzymatically generated $\mathrm{H}_{2} \mathrm{O}_{2}$ forms an electron-dense precipitate with cerous ions, revealing the sites of enzyme activity. In normal PMN stimulated by exposure to polystyrene (PS) particles, many cells show reaction product on the external surface of the plasma membrane and in the phagocytic vacuoles. Precipitate formation at both these sites occurs in significantly fewer cells from CGD patients, and it is less intense when it does occur.

\section{METHODS}

\section{Patients}

Three male patients with X-linked CGD were studied. In all three, diagnoses were established by characteristic clinical presentations and deficient nitroblue tetrazolium reduction by the granulocytes (36). Two of the patients were examined twice, after an interval of $6 \mathrm{mo}$, and the third was tested only once. A healthy male adult served as an internal control subject and was tested simultaneously with each CGD patient. Two additional controls, one female and one male, were examined separately.

\section{Preparation of cells}

Monolayers of PMN were prepared on glass cover slips by a modification of the technique of Harris (37). In brief, several drops of blood were allowed to clot at room temperature on a 22-mm diameter cover slip in a moist chamber and then incubated at $37^{\circ} \mathrm{C}$ for $30 \mathrm{~min}$. The blood clot and erythrocytes were rinsed from the cover slip with Hanks' balanced salt solution (Hanks' BSS, Microbiological Associates, Bethesda, Md.), $\mathrm{pH} 7.4$, at $4^{\circ} \mathrm{C}$, leaving numerous PMN attached to the glass. Venous blood, without anticoagulants, was used in the case of the CGD patients. Control PMN were obtained from venous blood or from a pricked finger. No differences were noted between the two methods, except that the finger prick blood preparations yielded slightly more PMN.

\section{Cytochemistry}

Localization of $\mathrm{H}_{2} \mathrm{O}_{2}$ in phagocytic vacuoles. To determine if $\mathrm{H}_{2} \mathrm{O}_{2}$ is present in the phagocytic vacuole of CGD granulocytes, a modification (12) of the DAB technique for the localization of peroxidase (38) was used on the PMN of one CGD patient and one normal control. The incubation medium contained $0.5 \mathrm{mg}$ DAB (Sigma Chemical Co., St. Louis, Mo.) per ml Hanks' BSS with an additional $1 \mathrm{mg} / \mathrm{ml}$ glucose and a 1:20 dilution of a $2.5 \%$ stock solution of PS spheres $(1.1 \mu \mathrm{m}$ diameter, The Dow 


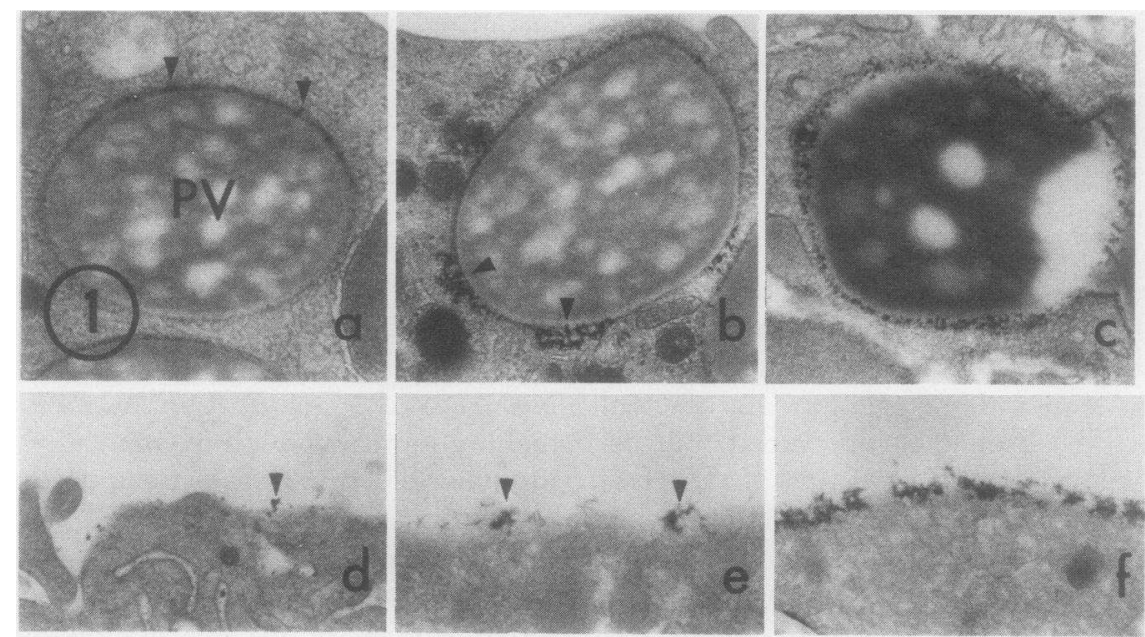

FIGURE 1 The amount of NADH oxidase activity in the phagocytic vacuoles (PV) (a-c) and on the plasma membrane (d-f), as expressed by the amount of $\mathrm{H}_{2} \mathrm{O}_{2}$-dependent cerium precipitation (arrows), was quantitated according to the criteria illustrated here. Figs. a and $\mathrm{d}$ show weakly $( \pm)$ reactive cells, $b$ and $\mathrm{e}$ are moderately $(+)$ reactive, and $\mathrm{c}$ and $f$ are strongly $(++)$ reactive. Magnification (a) $\times 26,800 ;$ (b) $\times 27,000 ;$ (c) $\times 29,600 ;$ (d) $\times 24,900 ;(e)$ $\times 25,200$; (f) $\times 17,300$.

Chemical Company, Indianapolis, Ind.). The stock PS solution was prepared by extensive $(72 \mathrm{~h})$ dialysis against twice distilled $\mathrm{H}_{2} \mathrm{O}$ and dilution to $2.5 \%$ of the original volume with sterile $0.8 \% \mathrm{NaCl}$. The $\mathrm{pH}$ of the incubation medium was adjusted to $7.3 ; 0.5 \mathrm{ml}$ was added to the PMN on each cover slip, followed by a 30 -min incubation at $37^{\circ} \mathrm{C}$ in a moist chamber. This incubation time was selected to insure adequate primary granule discharge into the phagocytic vacuole of CGD cells, since it has been shown that there is impaired degranulation during the early stages of phagocytosis (30). Controls consisted of the omission of DAB or particles from the medium or the inclusion of $2 \mathrm{mM}$ $\mathrm{KCN}$. In the latter case, the PMN were preincubated for $10 \mathrm{~min}$ at $37^{\circ} \mathrm{C}$ with the inhibitor in Hank's BSS, drained, and then reincubated in the test medium plus KCN. After incubation, the cells were rinsed briefly in Hanks' BSS at $4^{\circ} \mathrm{C}$ and prepared for electron microscopy.

Localization of $\mathrm{NADH}$-stimulated, $\mathrm{H}_{2} \mathrm{O}_{2}$-producing oxidase. The phagocytic stimulation of the $\mathrm{PMN}$ and the subsequent cytochemical determination of sites of $\mathrm{H}_{2} \mathrm{O}_{2}$ production (17) were performed on the PMN of all three CGD patients. Two were examined twice; one normal control was tested concurrently with each CGD, and two other normal controls were examined separately. Initially, monolayers of normal and CGD PMN were covered with $0.5 \mathrm{ml}$ per cover slip of a 1:20 dilution of $2.5 \%$ PS in Hanks' BSS plus an additional $1.0 \mathrm{mg} / \mathrm{ml}$ glucose and incubated $20 \mathrm{~min}$ at $37^{\circ} \mathrm{C}$ in a moist chamber. This was followed by a brief rinse at $4^{\circ} \mathrm{C}$ in $0.1 \mathrm{M}$ Tris-maleate buffer, $\mathrm{pH} 7.5$, with $7 \%$ sucrose. Incubation in the same buffer containing $1 \mathrm{mM}$ 3-amino-1,2,4-triazole (Aldrich Chemical Co., Inc., Milwaukee, Wis.) for $10 \mathrm{~min}$ at $37^{\circ} \mathrm{C}$ preceded a final incubation in the cytochemical medium. This contained $1 \mathrm{mM}$ 3-amino-1,2,4-triazole, $1 \mathrm{mM} \mathrm{CeCl}$, and 0.71 $\mathrm{mM}$ reduced pyridine nucleotide (Sigma Chemical Co.) in $0.1 \mathrm{M}$ Tris-maleate buffer, $\mathrm{pH} 7.5$, with $7 \%$ sucrose. Cells were incubated in this medium for $20 \mathrm{~min}$ at $37^{\circ} \mathrm{C}$. Parallel experiments were run in which NADH was omitted from the incubation medium. After incubation, the cells were rinsed briefly at $4^{\circ} \mathrm{C}$ in $0.1 \mathrm{M}$ Tris-maleate buffer, pH 7.5, with 7\% sucrose and prepared for electron microscopy.

Phagocytosis of a hydrogen peroxide-generating system. It has been shown that phagocytosis of PS beads coated with glucose oxidase results in an amelioration of the metabolic deficiencies of CGD granulocytes (34). This experiment was repeated and followed by a cerium incubation to see if $\mathrm{H}_{2} \mathrm{O}_{2}$ could be detected in the PMN of CGD patients. PS spheres were coated with glucose oxidase according to the method of Baehner et al. (34). Initially, this preparation was tested for glucose oxidase activity by suspending in glucose-free Krebs-Ringer phosphate, $\mathrm{pH}$ 7.4, and adding to this a small amount of glucose, DAB, and horseradish peroxidase (Sigma Chemical Co.). The precipitation of oxidized DAB indicated the peroxidegenerating capacity of the glucose oxidase on the particles. For phagocytosis by PMN from one CGD patient and normal control, the $2.5 \%$ stock solution of glucose oxidase-coated particles was diluted 1:20 in glucose-free Krebs-Ringer phosphate and added to the cell monolayers. After 20 min at $37^{\circ} \mathrm{C}$, the cells were rinsed with $0.1 \mathrm{M}$ Tris-maleate buffer, $\mathrm{pH} 7.5$, at $4^{\circ} \mathrm{C}$ and then incubated for $20 \mathrm{~min}$ at $37^{\circ} \mathrm{C}$ in $0.1 \mathrm{M}$ Tris-maleate buffer, $\mathrm{pH} 7.5$, with $1 \mathrm{mM} \mathrm{CeCl}{ }_{3}$. Sucrose, 3-amino-1,2,4-triazole, and NADH were not present in this medium. After the incubation, cells were rinsed briefly in buffer and prepared for electron microscopy.

\section{Electron microscopy}

After the appropriate cytochemical incubations, all cover slips were rinsed $2-3 \mathrm{~min}$ at $4^{\circ} \mathrm{C}$ in $0.1 \mathrm{M}$ Trismaleate buffer, pH 7.5, with $7 \%$ sucrose (no sucrose was used in glucose oxidase experiments in avoid possible contamination with glucose) and then placed directly into 2\% glutaraldehyde (electron microscopy grade, Polysciences, Inc., Warrington, $\mathrm{Pa}$.) in $0.1 \mathrm{M}$ cacodylate buffer, pH 7.3, with $5 \%$ sucrose at $4^{\circ} \mathrm{C}$ for $60 \mathrm{~min}$. In the cerium precipitation experiments, cells were then washed $1 \mathrm{~h}$ at $4^{\circ} \mathrm{C}$ 


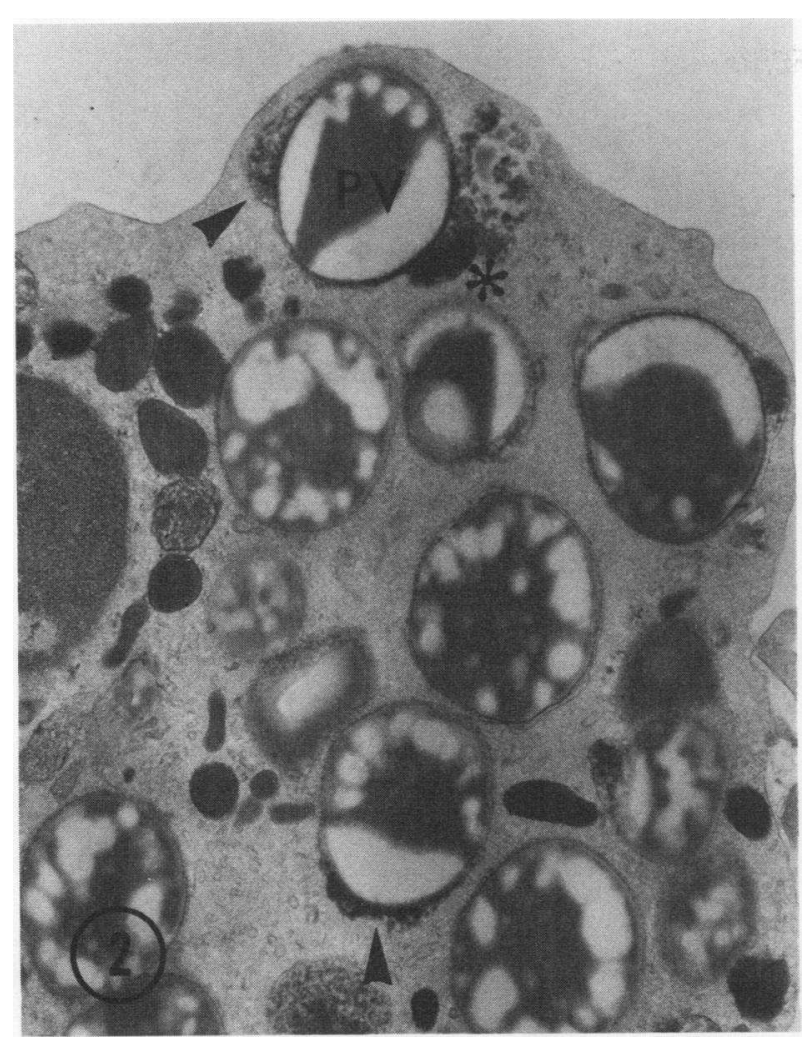

FIGURE 2 Normal PMN allowed to phagocytize PS and DAB for $30 \mathrm{~min}$ show electron dense reaction product (arrows), indicative of the presence of endogenous $\mathrm{H}_{2} \mathrm{O}_{2}$ within the phagocytic vacuoles (PV). Focal deposits of oxidized DAB are frequently seen within the phagocytic vacuole, probably representing the site of primary granule fusion with the phagosome $\left({ }^{*}\right)$, and thus the site of myeloperoxidase acting on the DAB and $\mathrm{H}_{2} \mathrm{O}_{2}$. Magnification $\times 18,000$.

in $0.1 \mathrm{M}$ cacodylate buffer with $5 \%$ sucrose at $\mathrm{pH}$ 6.0. All cells were rinsed overnight at $4^{\circ} \mathrm{C}$ in $0.1 \mathrm{M}$ cacodylate buffer, pH 7.3 , postfixed 60 min in $2 \%$ osmium tetroxide in the same buffer, dehydrated in graded ethanols, and then embedded in Epon 812 (Shell Chemical Co., New York) (39). After polymerization, specimens were taken directly from the oven and placed in liquid nitrogen for approximately $10 \mathrm{~s}$, resulting in a clean separation of the cells from the cover slip.

Thin sections were prepared with an LKB ultramicrotome (LKB Instruments, Inc., Rockville, Md.) using a diamond knife and examined in a Philips 200 electron microscope (Philips Electronic Instruments, Inc., Mount Vernon, N. Y.). For routine work, sections were left unstained to facilitate visualization of reaction product. When micrographs were to be taken, sections were stained with $4 \%$ aqueous uranyl acetate and lead citrate (40), 4 and 2 min, respectively.

\section{Quantification of NADH oxidase activity}

To assess the activity of NADH oxidase in normal and CGD PMN, appropriately treated cells (with and without exogenous NADH) were examined by electron microscopy. Only cells containing phagocytic vacuoles were counted. Depending on the amount of cerium precipitate on the surface of the cell or within the phagocytic vacuole, the cells were assigned to the following categories: negative $(-)$, weak $( \pm)$, moderate $(+)$, or strong $(++)$. The criteria for these evaluations are illustrated in Fig. 1 which shows approximately the amount of reaction product found in each category. The total numbers of reactive cells in each category were also recorded. All of the observations were made on a blind basis, and one thin section from each block was examined to avoid possible replication. All CGD data were pooled, as were the results of the seven experiments on the normal controls. The statistical comparisons were made using the chi-square test for association in a two-way table.

\section{RESULTS}

Hydrogen peroxide detection within phagocytic vacuoles (DAB localization). Examination of normal PMN after phagocytosis of PS in the presence of DAB revealed the presence of electron dense reaction product within the phagocytic vacuoles of a majority of the cells (Fig. 2). This oxidized DAB was located in the space between the particle and the membrane of the vacuole, frequently at a site of primary granule fusion. Occasionally reaction product

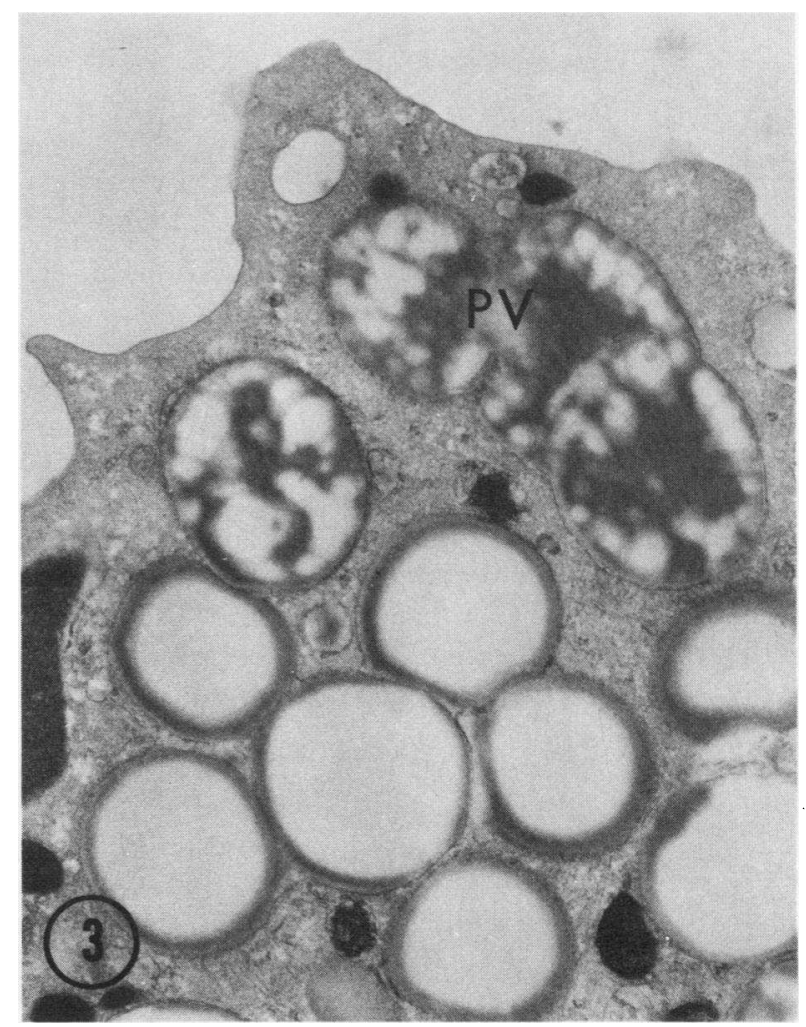

FIGURE 3 The lack of reaction product deposition within the phagocytic vacuoles (PV) of CGD PMN after uptake of PS and DAB indicates the absence of endogenous $\mathrm{H}_{2} \mathrm{O}_{2}$. Degranulation has occurred (arrow). Experimental conditions as for Fig.2. Magnification $\times 20,100$. 


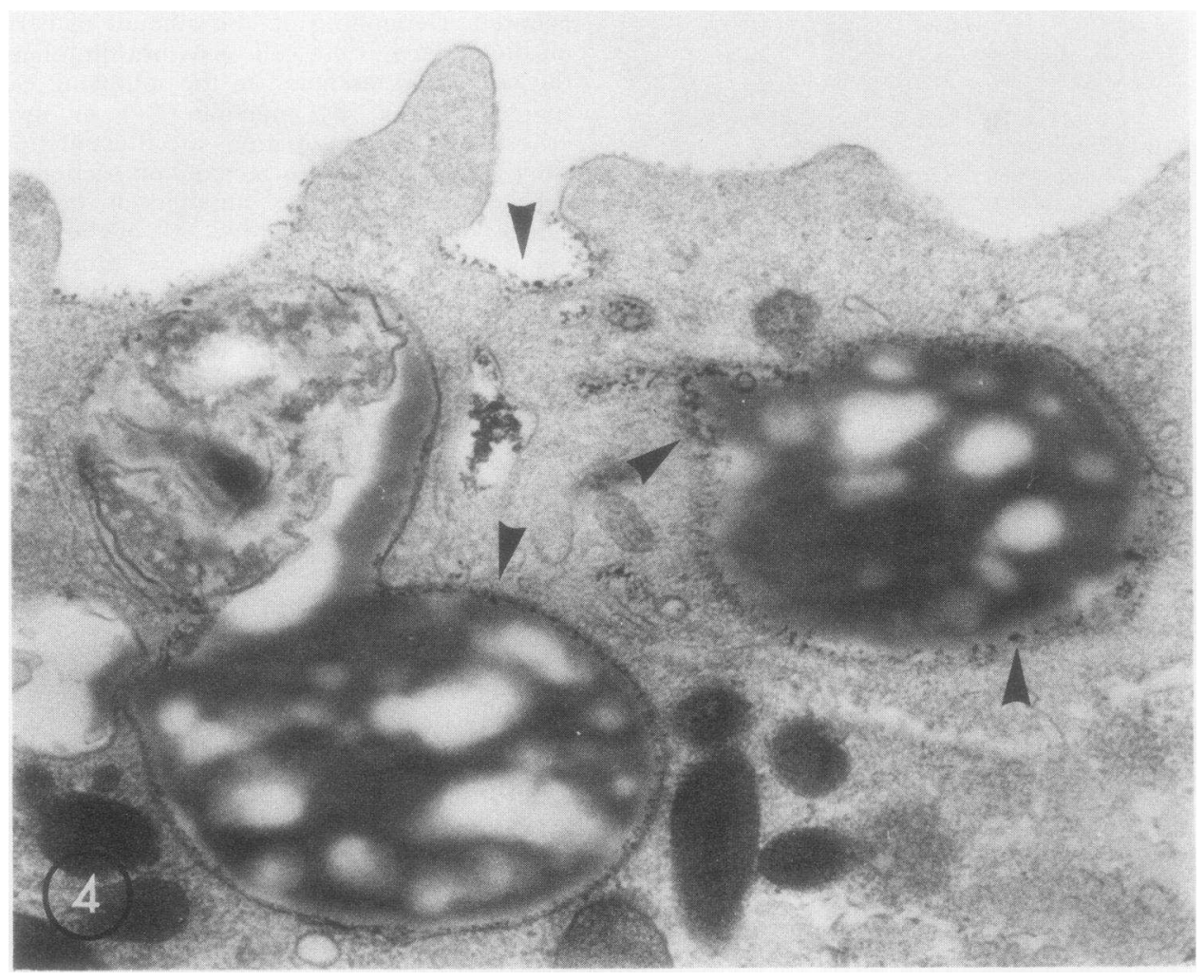

FIgURE 4 Normal PMN show NADH-dependent, $\mathrm{H}_{2} \mathrm{O}_{2}$-generating activity on the plasma membrane and within the phagocytic vacuole after uptake of PS. Incubation of phagocytically stimulated cells in a cytochemical medium containing $\mathrm{NADH}$ and $\mathrm{Ce}^{+++}$results in electron dense deposits (arrows) at the sites of enzyme activity. The enzymatically generated $\mathrm{H}_{2} \mathrm{O}_{2}$ reacts with $\mathrm{Ce}^{+++}$ions to form the electron dense $\mathrm{Ce}(\mathrm{OH})_{2} \mathrm{OOH}$ precipitate. This cell would be rated moderately $(+)$ reactive. Magnification $\times 48,100$.

was found in a channel connecting incompletely closed phagosomes to the cell surface or adsorbed to the cell surface itself. No reaction product was found within PMN exposed to DAB or PS alone. Addition of $\mathrm{KCN}$ to the incubation medium as an inhibitor of peroxidase activity greatly diminished both the amount of reaction product formed and the number of cells showing it. A majority of the KCN-treated cells were totally negative, although occasional phagocytic vacuoles were found to contain some oxidized DAB.

Uptake of PS and DAB by CGD granulocytes resulted in the formation of reaction product within a few phagocytic vacuoles, although almost all of these PMN were negative (Fig. 3). When electron dense deposits were found, they were generally associated with very large phagocytic vacuoles containing several PS particles. Elimination of either particles or DAB, or inclusion of $\mathrm{KCN}$ in the medium, resulted in a total loss of reactivity.

Sites of peroxide-producing activity (cerium localization). Phagocytically stimulated control PMN showed precipitates of $\mathrm{Ce}(\mathrm{OH})_{2} \mathrm{OOH}$ on the plasma membrane and within the phagocytic vacuoles after incubation in the complete cytochemical medium (Fig. 4) (17). Elimination of NADH from the medium reduced the amount of reaction product and the number of cells showing it in both these locations. PMN from patients with CGD, treated with PS, $\mathrm{Ce}^{+++}$, and NADH, appeared essentially negative with regard to surface activity (Fig. 5), although small amounts of peroxide-generating activity were found within the phagocytic vacuoles of some cells (Fig. 5, arrow). Elimination of NADH from the medium did not alter this distribution (Fig. 6). More cells showed reactive phagocytic vacuoles by this technique than with the DAB approach; presumably this discrepancy can be attributed to differing sensitivities of the two techniques.

Stimulation of cerium deposition by exogenous NADH and NADPH. A matter of concern in evaluating the specificity of the system with respect to the reduced pyridine nucleotides was the fact that, believing it important to maximize the NADPH oxidase activity, $\mathrm{Mn}^{++}$was included in the original evaluation of specificity with normal PMN (17). Subsequent to the 
original work, it was demonstrated that the effect of $\mathrm{Mn}^{++}$added to broken cell preparations is artifactual $(21,22)$. We have thus performed further experiments with the cytochemical technique, using NADPH or $\mathrm{NADH}$ as exogenous substrate, in the presence or absence of $\mathrm{Mn}^{++}$, with PS or zymosan particles (opsonized and unopsonized), and with normal or CGD PMN. In this system, only exogenous NADH was found to increase $\mathrm{H}_{2} \mathrm{O}_{2}$-dependent cerium deposition, and this only with normal, phagocytically stimulated PMN. Additional NADPH had no effect on the amount of cerium precipitated. Moreover, the presence or absence of manganese was found to be immaterial to the amount of reaction product formed with either NADH or NADPH.

Number of reactive PMN in controls and CGD patients. When the total number of cells showing NADH oxidase activity either on the surface or in the phagocytic vacuole is examined, there are several obvious distinctions. Table I shows a statistical comparison of surface and phagosomal reactivity of PMN from CGD patients and normal controls. The number of CGD PMN exhibiting NADH oxidase activity on the surface is significantly less than the control value. Although the difference is more noticeable in the presence of exogenous NADH, a significant difference is still found when it is eliminated from the cytochemical medium. The number of cells showing peroxide generation in the phagocytic vacuole is also reduced in CGD, and the difference between CGD and normal is significant either in the presence or absence of exogenous NADH.

Effect of exogenous NADH on the number of reactive PMN in controls and CGD patients. The effect of exogenous NADH on the reactivity of normal and CGD PMN is shown in Table I. The presence or absence of exogenous substrate makes no significant difference when one examines the number of CGD PMN exhibiting cerium deposits on the surface or in the phagocytic vacuole. This is not true with normal PMN; here one sees a significant reduction in the number of reactive cells, with regard to both sites, when NADH is omitted from the medium.

Assessment of NADH oxidase activity in control and $C G D P M N$. Table I illustrates the difference in the total number of cells exhibiting NADH oxidase activity, but there must be a consideration of the quantitative distribution of these reactive cells, based on the

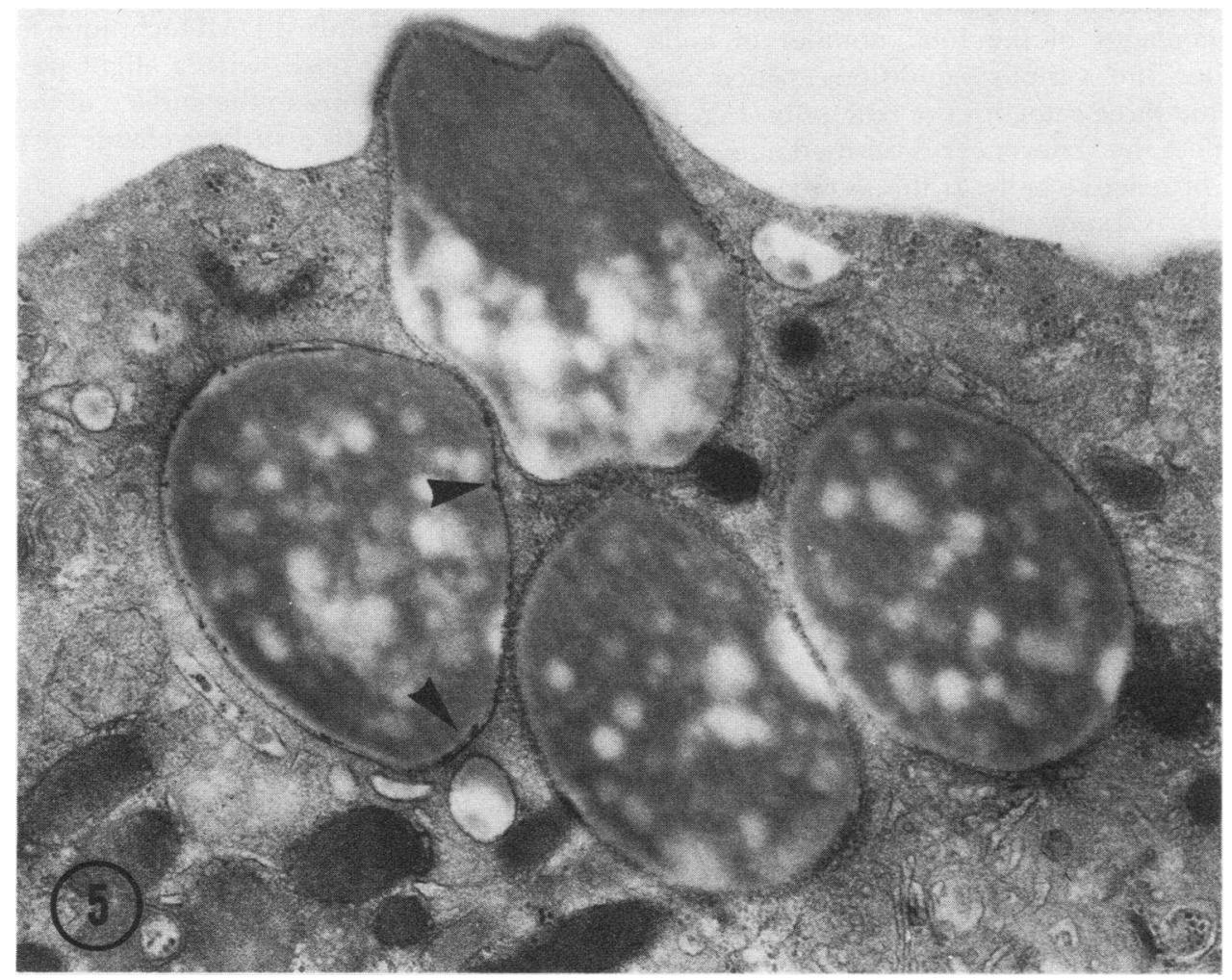

FIGURE 5 NADH oxidase activity in phagocytizing PMN from a CGD patient is found only within the phagosome, and the level of activity, deduced from the amount of precipitate (arrows), is much less than in the normal PMN (Fig. 4), giving it a weakly reactive rating $( \pm)$. Experimental conditions as for Fig. 4. Magnification $\times 38,900$. 


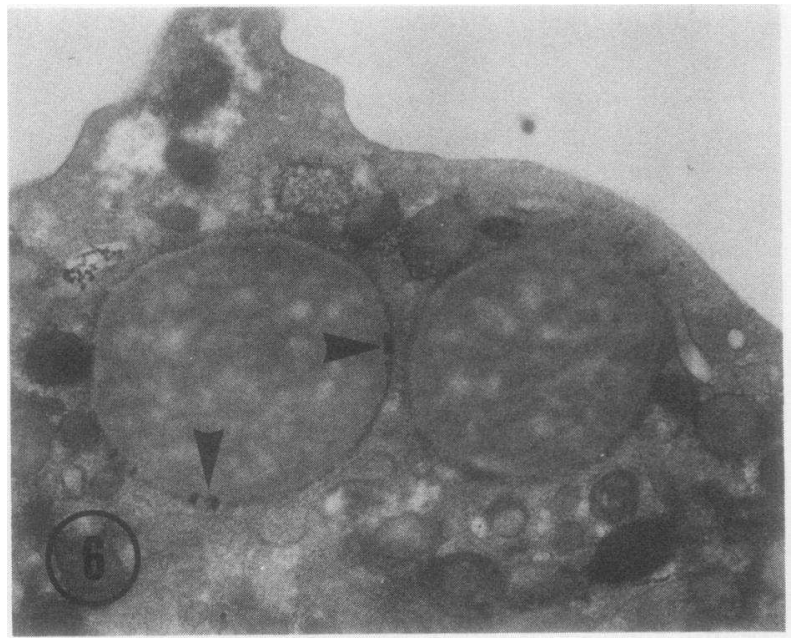

FIgURE 6 The elimination of NADH from the cytochemical medium causes no significant change in the amount of NADH oxidase activity (arrows) visible in CGD cells. This cell would be considered weakly reactive $( \pm)$. Experimental conditions as for Fig. 4, except NADH was omitted. Magnification $\times 24,400$.

amount of NADH oxidase activity they exhibit. Semiquantitative information derived from the examination of individual cells is presented in Fig. 7. These data show the percentages of the total number of cells examined under the various conditions which are distributed in the three categories of reactivity (Fig. 1). These data reflect the differences described above for total numbers of reactive cells. If the number of cells in each category is expressed as a percentage of the total number of reactive cells, one gets a distribution of the degree of NADH oxidase activity for comparing CGD and normal. This is shown in Fig. 8. In the presence of exogenous NADH, there are significantly fewer normal than CGD PMN showing weak, and more showing stronger NADH oxidase activity. This is true for both surface and phagocytic vacuole localization. Omission of NADH from the incubation medium does not change this relationship for plasma membrane and phagocytic vacuole reactivity. Significantly more CGD PMN are found in the weakly reactive category and fewer CGD than normal PMN are found in the more strongly reactive classifications.

Phagocytosis of glucose oxidase-coated particles. When PMN from CGD patients phagocytized PS spheres coated with glucose oxidase and were then incubated in the cytochemical medium containing only cerous ions, most of the cells contained reaction product, indicative of hydrogen peroxide generation, within nearly all their phagocytic vacuoles (Fig. 9). The surface of the cell was not reactive. Normal PMN treated in this manner showed cerium deposits in the phagocytic vacuoles and on the surface, the latter being due presumably to NADH oxidase activity utilizing endogenous substrate. Phagocytic vacuole deposits are due to glucose oxidase as well as NADH oxidase activity.

This confirms the observations of Baehner et al. (34) and shows that $\mathrm{H}_{2} \mathrm{O}_{2}$ can be detected cytochemically within the phagocytic vacuoles of CGD cells when it is present. This reduces the possibility of some peculiarity in these cells preventing the detection of NADH oxidase by reaction between peroxide and cerous ions.

\section{DISCUSSION}

Leukocytes from patients with CGD fail to generate $\mathrm{H}_{2} \mathrm{O}_{2}$ (25) and $\mathrm{O}_{2}^{-}$(28) during phagocytosis, although the phagocytic capacity and rate of degranulation appear to be relatively normal. As a result, there is a diminished microbicidal capacity, for $\mathrm{H}_{2} \mathrm{O}_{2}$, and possibly $\mathrm{O}_{2}^{-}$, are important for adequate bacterial killing (8). Where the responsibility for this oxidative deficiency lies is unclear, as is which enzyme is responsible for the oxidative burst in normal PMN. Both NADH and NADPH oxidase have been reported to have reduced levels in $\operatorname{CGD}(15,16,23,32,33)$.

The reduced $\mathrm{H}_{2} \mathrm{O}_{2}$-generating capacity of CGD PMN has been verified cytochemically by a modification (12) of the standard DAB technique for peroxidase (38). Presumably DAB, with a slight positive charge, enters the cell bound to the surface of the PS particle, which has a negative surface charge at physiological

\section{TABLE I}

Comparison of Percentages of PMN from Control and CGD Individuals Showing NADH Oxidase Activity on the Plasma Membrane and within the Phagocytic Vacuole in the Presence and Absence of Exogenous NADH*

\begin{tabular}{lcccccc}
\hline & \multicolumn{2}{c}{ Plasma membrane } & & \multicolumn{2}{c}{ Phagocytic vacuole } \\
\cline { 2 - 3 } PMN source & $\begin{array}{c}\text { With } \\
\text { NADH }\end{array}$ & $\begin{array}{c}\text { Without } \\
\text { NADH }\end{array}$ & & $\begin{array}{c}\text { With } \\
\text { NADH }\end{array}$ & $\begin{array}{c}\text { Without } \\
\text { NADH }\end{array}$ \\
\hline Control & 45.2 & $30.5 \neq$ & & 62.7 & 44 \\
CGD & 7.2 & 8.7 & & 30.3 & 30.7
\end{tabular}

* Numbers of cells examined: control + NADH, 606; control - NADH, 586; CGD + NADH, 512; CGD - NADH, 381 .

\& $P$ values from chi-square test for association in two-way table. Significantly more control PMN are reactive than CGD cells at both sites examined and in the presence and absence of exogenous NADH $(P<0.001$ in all cases). The omission of NADH from the incubation medium significantly reduces the percentage of control PMN showing plasma membrane $(P<0.001)$ and phagocytic vacuole $(P<0.001)$ reactivity, but there is not a significant change in CGD PMN (plasma membrane, $P<0.43$; phagocytic vacuole, $P<0.89$ ). 


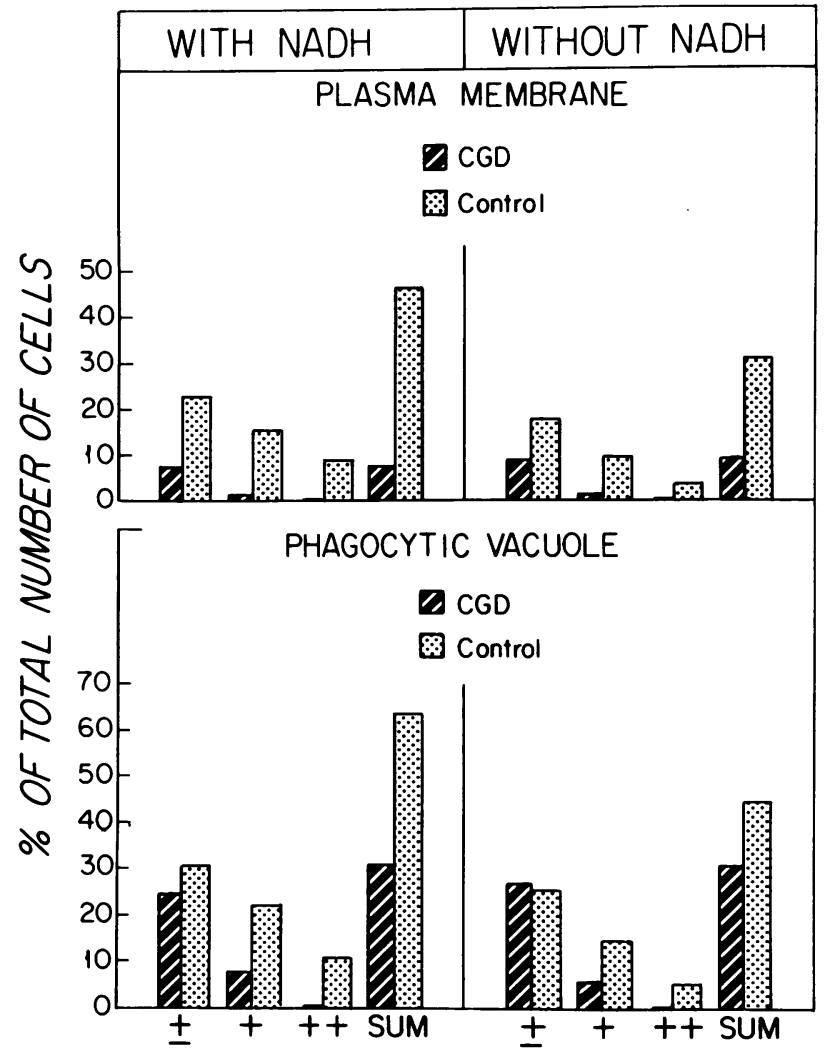

FIgURE 7 Comparison of the number of control and CGD PMN showing $\mathrm{H}_{2} \mathrm{O}_{2}$-dependent reaction product on the plasma membrane and within the phagocytic vacuole. Both the distribution of these cells within the three categories, reflecting their relative NADH oxidase activities, and the sum of the reactive cells from all categories are shown. Data are expressed as the percent of the total number of cells examined. ( \pm , weak, + , moderate; ++ , strong).

$\mathrm{pH}$ (41). The test is dependent upon the presence in the phagocytic vacuole of endogenous peroxide acting as the substrate for myeloperoxidase in the oxidation of DAB. It is known that CGD PMN have normal levels of myeloperoxidase and that degranulation delivers this peroxidase to the phagosome (42), although there appears to be a brief lag period (30). CGD PMN clearly show greatly diminished amounts of reaction product in the phagocytic vacuoles as compared to normal, a result which must be due to a lack of $\mathrm{H}_{2} \mathrm{O}_{2}$. The negative $\mathrm{KCN}$ control also verifies the specificity of the reaction.

As a result of the information derived from the DAB cytochemistry, the sites of NADH oxidase activity in normal and CGD PMN were investigated using a recently developed cytochemical technique. This technique depends upon the precipitation of cerium by $\mathrm{H}_{2} \mathrm{O}_{2}$, and the preference of the enzyme for NADH has been documented (17, and above). The results with the cerium-based method support the ob- servations made with DAB, although there are two important differences. First, the cerium technique shows actual sites of peroxide generation instead of merely the presence or absence of $\mathrm{H}_{2} \mathrm{O}_{2}$. Secondly, semiquantitation of amounts of reaction product, a direct indication of oxidase activity, is possible. The differences in NADH oxidase activity between normal and CGD PMN are obvious when one examines the number of cells showing reaction product on the plasma membrane or within the phagocytic vacuole. There is a significantly higher number of reactive cells in the control as compared to CGD, both in the presence and absence of NADH. This means that fewer CGD PMN are capable of responding to a phagocytic stimulation by generating increased amounts of $\mathrm{H}_{2} \mathrm{O}_{2}$.

The effect of NADH in the cytochemical medium on the number of reactive cells is of interest. Its presence results in significantly more normal PMN being reactive than when it is omitted, implying that the avail-

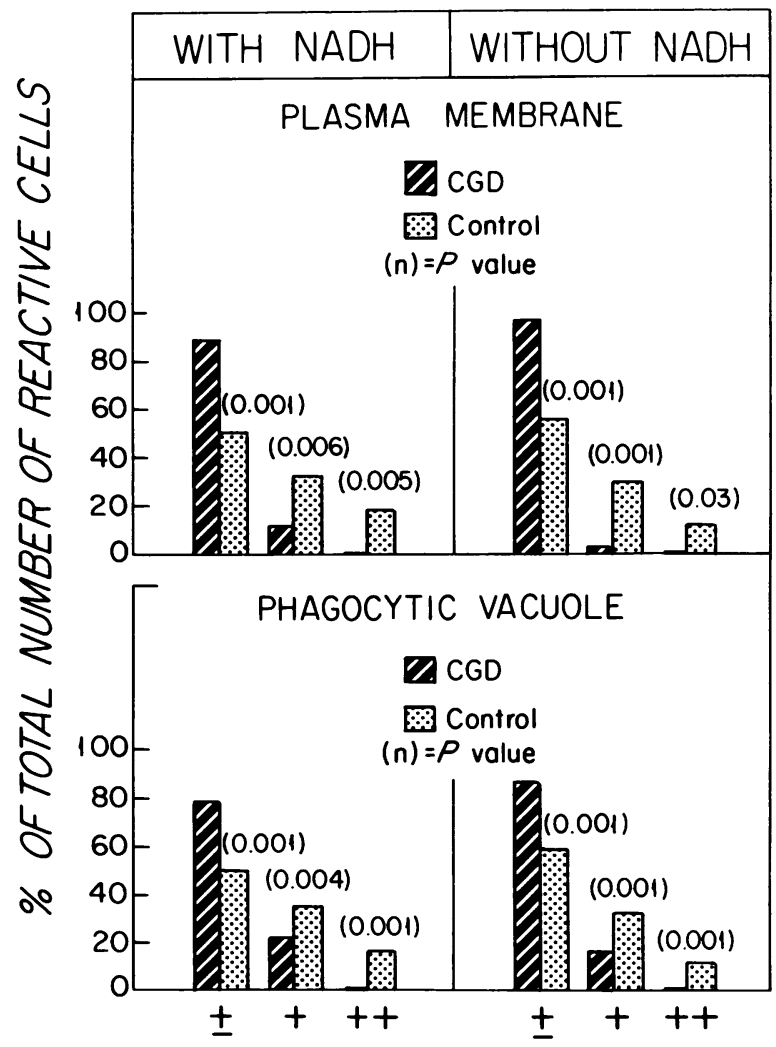

FIGURE 8 Comparison of the distributions of control and CGD PMN based on the amount of $\mathrm{H}_{2} \mathrm{O}_{2}$-dependent reaction product found on the surface and within the phagocytic vacuole. Each bar represents the number of reactive cells within each classification, expressed as a percentage of the total number of reactive cells. Numbers in parentheses are $P$ values from a chi-square test; all differences are significant. 


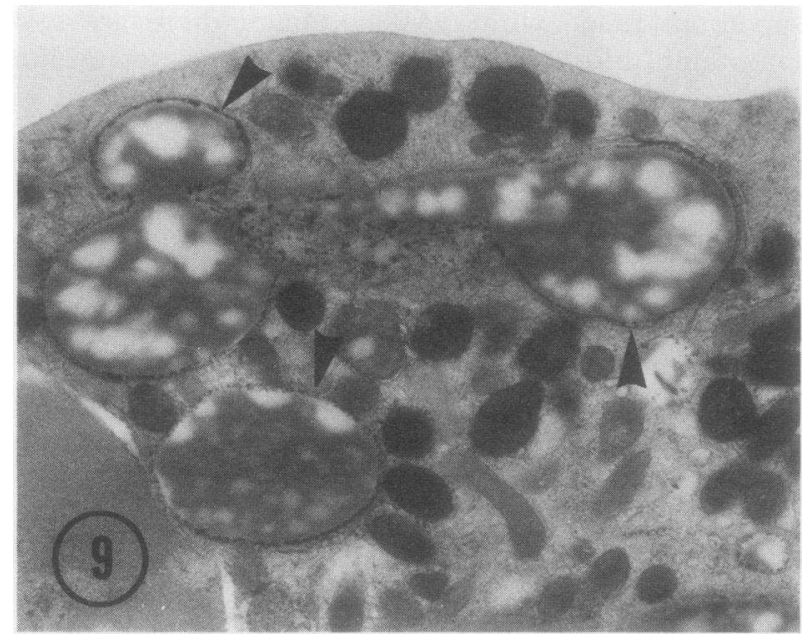

Figure 9 CGD PMN tested for the presence of $\mathrm{H}_{2} \mathrm{O}_{2}$ by the $\mathrm{Ce}^{+++}$technique after phagocytosis of glucose oxidase-coated PS show reaction product (arrows) in many of the phagocytic vacuoles although the surface remains negative. This shows that the glucose oxidase does generate $\mathrm{H}_{2} \mathrm{O}_{2}$ within the phagosome and that intracellular peroxide can be detected within the CGD PMN. Magnification $\times 17,700$.

ability of substrate limits the amount of oxidase activity in normal PMN. Presumably exogenous NADH acts to increase the amount of $\mathrm{H}_{2} \mathrm{O}_{2}$ being generated, thereby increasing the number of cells producing detectable levels of peroxide. This does not appear to be the case with CGD PMN, implying that the amount or activity of the enzyme is limiting, and the availability of endogenous NADH is sufficient for maximal operation of the decreased peroxide-generating mechanisms. Not only are a greater proportion of normal PMN found to be reactive compared to CGD cells, but they are also capable of generating greater amounts of $\mathrm{H}_{2} \mathrm{O}_{2}$. This is true both at the level of the plasma membrane and the phagocytic vacuole.

The cytochemical evidence presented here supports the conclusions of others that there is a diminution of NADH-oxidizing activity $(15,16,33)$ and $\mathrm{H}_{2} \mathrm{O}_{2}$-generating capacity $(25,27)$ in phagocytically stimulated PMN from patients with CGD. The data derived from biochemical studies are averages based on a large number of cells. But the cytochemical results, derived from observations on individual cells, present a more definite picture of this reduced activity. Cytochemically the total number of CGD PMN showing NADH oxidase activity on the surface or in the phagocytic vacuole is reduced, as is the specific activity of the individual cells that are reactive. Certainly the amount of $\mathrm{H}_{2} \mathrm{O}_{2}$ produced by a $\mathrm{PMN}$ is equally as important in the host's defense mechanism as is the number of PMN involved.
There are some CGD PMN which appear to generate amounts of $\mathrm{H}_{2} \mathrm{O}_{2}$ comparable to normal PMN and hence would seem capable of microbicidal activity. In view of this, perhaps the defect in CGD, at one level at least, is that there simply are not a sufficient number of these bactericidally competent cells to serve as an adequate defense mechanism. This observation may also clarify the previously reported observation on the variations in the severity of the defect (31). Individual differences may be reflecting differences in the number of PMN capable of generating adequate amounts of $\mathrm{H}_{2} \mathrm{O}_{2}$. In this regard, preliminary cytochemical observations on a female carrier (heterozygote) of CGD show values for NADH oxidase activity which are intermediate between normal and disease levels, in terms of numbers of reactive cells.

It is difficult to explain the large percentage of normal PMN in which no NADH oxidase activity can be detected after phagocytosis. This may be an accurate reflection of the actual activity of these cells. For example, the unreactive ones may be immature cells, for it is not known when in the life span of the cell this enzyme is produced or active. Or it may be artifactual, i.e., the plane of the section fails to pass through sites of reaction product deposition or the sensitivity of the technique itself is limiting.

No cytochemical data are available regarding NADPH oxidase activity in CGD PMN, because no augmented peroxide generation can be detected by cerium with NADPH as a substrate in control (17) and CGD PMN. Further, it would be useful to be able to carry out the cerium-based detection of $\mathrm{H}_{2} \mathrm{O}_{2}$ production at the level of the light microscope, for the reaction is quite specific and should provide another diagnostic test for CGD. Work is currently underway to convert the cerium precipitate to one more suitable for this approach.

\section{ACKNOWLEDGMENTS}

The authors are indebted to Dr. Bernard M. Babior, Dr. Dana M. Whitten, and Dr. Edward J. Goetzl for providing access to the CGD blood, and to Dr. David Drath for helpful suggestions and comments on the manuscript. We also wish to acknowledge the excellent technical assistance and endurance of Ms. Wendy Wren and the photographic assistance of Mr. Robert Rubin.

This research was supported by grant CA 14723 from the National Institutes of Health, U. S. Public Health Service.

\section{REFERENCES}

1. Sbarra, A. J., and M. J. Karnovsky. 1959. The biochemical basis of phagocytosis. I. Metabolic changes during the ingestion of particles by polymorphonuclear leukocytes. J. Biol. Chem. 234: 1355-1362.

2. Babior, B. M., R. S. Kipnes, and J. T. Curnutte. 1973. 
Biological defense mechanisms. The production by leukocytes of superoxide, a potential bactericidal agent. J. Clin. Invest. 52: 741-744.

3. Curnutte, J. T., and B. M. Babior. 1974. Biological defense mechanisms. The effect of bacteria and serum on superoxide production by granulocytes. J. Clin. Invest. 53: $1662-1672$.

4. Iyer, G. Y. N., M. F. Islam, and J. H. Quastel. 1961. Biochemical aspects of phagocytosis. Nature (Lond.). 192: 535-541.

5. Paul, B., and A. J. Sbarra. 1968. The role of the phagocyte in host-parasite interactions. XIII. The direct quantitative estimation of $\mathrm{H}_{2} \mathrm{O}_{2}$ in phagocytizing cells. Biochim. Biophys. Acta. 156: 168-178.

6. Karnovsky, M. L:, 1962. Metabolic basis of phagocytic activity. Physiol. Rev. 42: 143-168.

7. Root, R. K., J. Metcalf, N. Oshino, and B. Chance. 1975. $\mathrm{H}_{2} \mathrm{O}_{2}$ release from human granulocytes during phagocytosis. I. Documentation, quantitation, and some regulating factors. J. Clin. Invest. 55: 945-955.

8. Klebanoff, S. J. 1975. Antimicrobial mechanisms in neutrophilic polymorphonuclear leukocytes. Semin. Hematol. 12: $117-142$.

9. Root, R. K., and T. P. Stossel. 1974. Myeloperoxidasemediated iodination by granulocytes. Intracellular site of operation and some regulating factors. J. Clin. Invest. 53: 1207-1215.

10. Klebanoff, S. J., and C. B. Hamon. 1972. Role of myeloperoxidase-mediated antimicrobial systems in intact leukocytes. J. Reticuloendothel. Soc. 12: 170196.

11. Sbarra, A. J., B. B. Paul, A. A. Jacobs, R. R. Strauss, and G. W. Mitchell, Jr. 1972. Biochemical aspects of phagocytic cells as related to bactericidal function. J. Reticuloendothel. Soc. 11: 492-502.

12. Briggs, R. T., M. L. Karnovsky, and M. J. Karnovsky. 1975. Cytochemical demonstration of hydrogen peroxide in polymorphonuclear leukocyte phagosomes.J. Cell Biol. 64: 254-260.

13. Cagan, R. H., and M. L. Karnovsky. 1964. Enzymatic basis of the respiratory stimulation during phagocytosis. Nature (Lond.). 204: 255-257.

14. Baehner, R. L., N. Gilman, and M. L. Karnovsky. 1970. Respiration and glucose oxidation in human and guinea pig leukocytes: comparative studies. J. Clin. Invest. 49: $692-700$.

15. Baehner, R. L., and M. L. Karnovsky. 1968. Deficiency of reduced nicotinamide-adenine dinucleotide oxidase in chronic granulomatous disease. Science (Wash. D. C.). 162: $1277-1279$.

16. Segal, A. W., and T. J. Peters. 1976. Characterization of the enzyme defect in chronic granulomatous disease. Lancet. 1: 1363-1365.

17. Briggs, R. T., D. B. Drath, M. L. Karnovsky, and M. J. Kamovsky. 1975. Localization of NADH oxidase on the surface of human polymorphonuclear leukocytes by a new cytochemical method. J. Cell Biol. 67: 566-586.

18. Takanaka, K., and P. J. O'Brien. 1975. Mechanisms of $\mathrm{H}_{2} \mathrm{O}_{2}$ formation by leukocytes. Evidence for a plasma membrane location. Arch. Biochem. Biophys. 169: 428435.

19. Patriarca, P., R. Cramer, P. Dri, L. Fant, R. E. Basford, and F. Rossi. 1973. NADPH oxidizing activity in rabbit polymorphonuclear leukocytes: localization in azurophilic granules. Biochem. Biophys. Res. Commun. 53: 830-837.

20. Patriarca, P., R. Cramer, S. Moncalvo, F. Rossi, and D.
Romeo. 1971. Enzymatic basis of metabolic stimulation in leukocytes during phagocytosis: the role of activated NADPH oxidase. Arch. Biochem. Biophys. 145: 255262.

21. Curnutte, J. T., M. L. Karnovsky, and B. M. Babior. 1976. Manganese-dependent NADPH oxidation by granulocyte particles. The role of superoxide and the nonphysiological nature of the manganese requirement. J. Clin. Invest. 57: 1059-1067.

22. Patriarca, P., P. Dri, K. Kakinuma, F. Tedesco, and F. Rossi. 1975. Studies on the mechanism of metabolic stimulation in polymorphonuclear leukocytes during phagocytosis. I. Evidence for superoxide anion involvement in the oxidation of $\mathrm{NADPH}_{2}$. Biochim. Biophys. Acta. 385: 380-386.

23. Curnutte, J. T., R. S. Kipnes, and B. M. Babior. 1975. Defect in pyridine nucleotide dependent superoxide production by a particulate fraction from the granulocytes of patients with chronic granulomatous disease. N. Engl. J. Med. 293: 628-632.

24. Babior, B. M., J. T. Curnutte, and B. Jane McMurrich. 1976. The particulate superoxide-forming system from human neutrophils. Properties of the system and further evidence supporting its participation in the respiratory burst. J. Clin. Invest. 58: 989-996.

25. Holmes, B., A. R. Page, and R. A. Good. 1967. Studies of the metabolic activity of leukocytes from patients with a genetic abnormality of phagocytic function. $J$. Clin. Invest. 46: 1422-1432.

26. Nathan, D. G., and R. L. Baehner. 1971. Disorders of phagocytic cell function. Prog. Hematol. 7: 235-254.

27. Homan-Müller, J. W. T., R. S. Weening, and D. Roos. 1975. Production of hydrogen peroxide by phagocytizing human granulocytes. J. Lab. Clin. Med. 85: 198-207.

28. Curnutte, J. T., D. M. Whitten, and B. M. Babior. 1974. Defective superoxide production by granulocytes from patients with chronic granulomatous disease. N. Engl. J. Med. 290: 593-597.

29. Weening, R. S., R. Wever, and D. Roos. 1975. Quantitative aspects of the production of superoxide radicals by phagocytizing human granulocytes. J. Lab. Clin. Med. 85: 245-252.

30. Gold, S. B., D. M. Hanes, D. P. Stites, and H. H. Fudenberg. 1974. Abnormal kinetics of degranulation in chronic granulomatous disease. N. Engl. J. Med. 291: 332-337.

31. Nathan, D. G., R. L. Baehner, and D. K. Weaver, 1969. Failure of nitro blue tetrazolium reduction in the phagocytic vacuoles of leukocytes in chronic granulomatous disease. J. Clin. Invest. 48: 1895-1904.

32. Hohn, D. C., and R. I. Lehrer. 1975. NADPH oxidase deficiency in X-linked chronic granulomatous disease. J. Clin. Invest. 55: 707-713.

33. Baehner, R. L., and D. G. Nathan. 1967. Leukocyte oxidase: defective activity in chronic granulomatous disease. Science (Wash. D. C.). 58: 835-836.

34. Baehner, R. L., D. G. Nathan, and M. L. Karnovsky. 1970. Correction of metabolic deficiencies in the leukocytes of patients with chronic granulomatous disease. J. Clin. Invest. 49: 865-870.

35. Johnson, R. B., Jr., and R. L. Baehner. 1970. Improvement of leukocyte bactericidal activity in chronic granulomatous disease. Blood. 35: 350-355.

36. Baehner, R. L., and D. G. Nathan. 1968. Quantitative nitroblue tetrazolium test in chronic granulomatous disease. N. Engl. J. Med. 278: 971-976. 
37. Harris, H. 1953. Chemotaxis of granulocytes. J. Pathol. Bacteriol. 66: 135-146.

38. Graham, R. C., Jr., and M. J. Karnovsky. 1966. The early stages of absorption of injected horseradish peroxidase in the proximal tubules of mouse kidney: ultrastructural cytochemistry by a new technique. J. Histochem. Cytochem. 14: 291-302.

39. Luft, J. H. 1961. Improvements in epoxy resin embedding methods. J. Biophys. Biochem. Cytol. 9: 409-414.

40. Reynolds, E. S. 1963. The use of lead citrate at high
pH as an electron-opaque stain in electron microscopy. J. Cell Biol. 17: 208-212.

41. Stossel, T. P., R. J. Mason, J. Hartwig, and M. Vaughan. 1972. Quantitative studies of phagocytosis by polymorphonuclear leukocytes: use of emulsions to measure the initial rate of phagocytosis. J. Clin. Invest. 51: 615-624.

42. Baehner, R. L., M. J. Karnovsky, and M. L. Karnovsky. 1969. Degranulation of leukocytes in chronic granulomatous disease. J. Clin. Invest. 48: 187-192. 